but that it might be explained by various circumstances not to be entered into here. What is of importance about the results obtained from the adults is the striking way in which they support the statistics of total deafness in children. With an adult there is not the same danger of misinterpreting the reactions to a test that there is in a child. Both returns (of children and adults) prove to the hilt that more than one-half of all deaf-mutes are totally deaf.

TABLE XIV.-Consanguinity, Heredity, \&c. Adults (57).

\begin{tabular}{|c|c|c|}
\hline \multirow{2}{*}{$\begin{array}{l}\text { Unmarried. } \\
35 .\end{array}$} & Married. & Wife. \\
\hline & 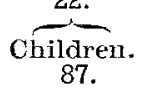 & $\begin{array}{l}\text { Deat. Hearing. } \\
17 . \quad 5 .\end{array}$ \\
\hline
\end{tabular}

In connexion with this table I beg to incorporate the following items from Mr. Wright's statistics :-

Consanguinity.

1. First cousins. Result : four deaf and dumb children, one of whom married and has three deaf and dumb children.

2. First cousins. Result : three deaf and dumb children and one deaf grandchild.

3. First cousins. Result : one deaf and dumb child; rest of large family all hear and speak.

4. Tro cases of first cousins. Result : each had one deaf and dumb child.

Deaf Parentage.

1. Father and mother both born deaf. Result : five deaf and dumb children and one hearing child.

2. Parents both deaf and dumb. Result: one deaf and dumb child (mother born deaf, father's case not known).

3. Woman who was born deaf married a man who lost his hearing at seven from fever. Result : large family, none of whom are deaf and dumb.

4. Four deaf and dumb in the family; father and mother both hear and speak, bat mother has two sisters deaf and dumb.

5. One girl has deaf and dumb mother and two deaf and dumb aunts.

6. One girl has deaf and dumb aunt and uncle.

7. Two children have each a deaf and dumb cousin.

The remaining statistics, principally recorded by Mr. Wright, the beadmaster of the institution, and referring to matters requiring more space than this paper will permit, I append without further remark :-

Oat of 124 deaf-mutes in the institution, 48 were females, 76 boys. Considering that there are more females than males in a general population the contrary state in the deaf-mute population is curious. One explanation given is that the male organ of hearing goes through stronger foetal development, and is therefore more subject to pathological changes. Again, males are more frequently affected by acute brain diseases than females, especially cerebro-spinal meningitis.

There were 81 children as the result of the marriage of 22 deaf mutes whose wives were mostly deaf-mutes: 95 per cent. of these children had normal hearing, while 12 per cent. were deat clearly-a larger proportion of deaf mutes than would be expected amongst the children of the same number of crdinary marriages. A few interesting gtatistics of side relationship are given by Mr. Wright, proving that inheritance plays a part as an etiological factor, remote it may be, in the pathological condition of deafmutism. Too intimate relationship in marriage is another predisposing cause and furnishes more deaf-mutes than the children the result of marriage among deaf-mutes themselves.

The headmaster knows of 23 cases of the inter-marriage of deaf and dumb who have hearing children only.

In 1 family there are 6 deaf and dumb children.

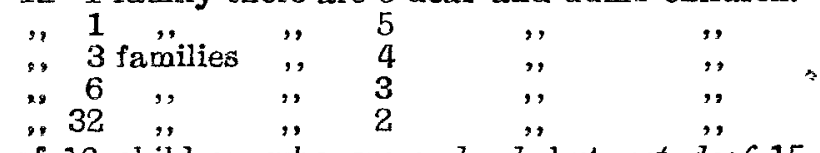

Ont of 16 children who were $d_{u m b} b$ but not deaf 15 were found to be deficient in intellect.

A great deal might be said about these remoter causes of deaf-mutism - e.g., consanguinity, heredity, terrestrial effluvia, unfavourable social and hygienic conditions, \&c., etiolo zical factors which are chiefly considered in connexion with the congenital form of deaf-mutism. 'The direct causes of this form require more inquiry ; but judging from necropsies it would seem that the same direct agencies at work in producing the majority of the acquired forms-viz., "mycotic infections "- might be legitimately accepted as the direct agents also in the production of many congenital cases of deaf-mutism.

The large number of instances of mutism met with in the institution is worthy of notice. There were two cases met with in the present inquiry. The muteness is no doubt dependent on disease of the centres for speech in the cerebrum. This, however, is a question quite foreign to the present inquiry. Newcastle-on-Tyne.

\section{RAINFALL AND SEASONAL CHANGE IN INDIA. ${ }^{1}$}

BY H. HERBERT, F.R.C.S. FNG., SURGEON-CAPTAIN, I.M.S.

I HAVE chosen this subject because of all the causes of seasonal change in the prevalence of cholera rainfall conditions are the most powerful. The influence of rainfall on cholera depends almost entirely on its effect on water supplies; but the rain registers are in India the most readily available indices of the condition of water.supplies generally. Every season of the year is the cholera season of some part of India; and the main object of this paper is to show that, however diverse these cholera seasons may be, one condition, or the nearest possible approach to it, characterises each in its particular district. In each locality a certain definite condition as regards rainfall and its effect on water levels is most suited to the development of cholera; and variations from this supply, either in excess or in defect, are progressively unfavourable. It is not possible at present to give an exact definition of this most favourable possible condition; bot it may be approximately and provisionally stated as that condition which provides localised collections of stagnant surface water, with subsoil water nowhere far below the surface, and it must be understood that in some parts of India only an approach to this state is possible. There may be always to some degree a defect or excess in rainfall. In a short communication of this kind the evidence adducible must be curtailed. It is here limited to instances where over large areas the physical and meteorological conditions are suffciently alike to maintain the one type of cholera season. I will begin with places where cholera particularly avoids the rainy season. Lower Bengal (meteorological area) and the valleys of Assam are the more striking examples. Cholera is here perennial. Bat in Lower Bengal the heavier mortality is collected into a double-headed rise that nearly fills the interval between successive rainy seasons. In the province of Assam the dip between the two maxima is deeper, producing two separate cholera seasons. Bryden's ${ }^{2}$ description of his endemic area applies also to the Assam valleys: "The ground moisture is always within a few feet or inches from the surface, and it requires only the waters of inundation derived from the striking of the monsoon on the hills to place vast tracts of it under water." Geologically it is "a series of beds of silt. ...... These beds are generally quite or very nearly horizontal. ...... Not one of these places does or can afford any natural drainage." 3

As one goes hence westward through the Gangetic plains the rainfall gets lighter. The mortality from cholera falls (see table), and its season changes. Cold weather cholera first disappears. Further west "spring cholera" becomes insignificant, that of the monsoon attaining prominence. In the Punjab it is, except in years of Hurdwar fair epidemics, nearly limited to the rainy season. As Lewis and Cunning. ham" express it: "In the upper part of India ..... the maximum prevalence of the disease occurs just at those periods when the soil-conditions most closely approach those in Calcutta when in its driest state--viz., during and towards the end of the rains." We have gone from one extreme to the other: from a rainfall of sixty or seventy inches to one of twenty inches or less; from one of the heaviest cholera mortalities to the lightest in India; from a prevalence that is

1 A paper read at the International Congress of Hygiene and Demography, Budapest, before the Section of Tropical Disease and 3 Dr. Oldham's memorandum, guoted by Lewis and Cunningham. 4 Cholera in relation to certain Physical Phenomena. 
perennial with exacerbations to one epidemic only in a limited season; from a dry season cholera to a rainy season cholera; and from the alluvial foam of the Gangetic delta, containing stagnant water close beneath the surface, to a land where "the high intermediate plain stretches from stream to stream in a broad and nndulating expanse of sterile sandhills.

In these sterile tracts the well water is in many places from 50 to 120 or more feet below the surface." "It is here that the south-west monsoon is lost. Bellew ${ }^{6}$ says: "The districts (of the Punjab) in which cholera is more or less persistently present, and in which it prevails with activity in each successive epidemic year, are situated in the area traversed by the currents of the south-west monsoon." It should perhaps be noted that these eastern districts differ geologically from the above-quoted description. They are a continuation of the Gangetic plains, "the tract of the great Kunkar clay...... water containing only in its interstratified sandbeds." 7 Bellew ${ }^{8}$ also states of this province: "Most of the districts in which it is found that cholera is more or less steadily persistent all through the year are characterised by the presence of greater or less areas covered either by marshes or by stagnant pools, or by obstructed drainage producing a water-logged soil, or by canal irrigation." The extreme immunity of this province is found in a wide stretch of country comprising the Mooltan division and the neighbouring trans-Indus districts. They are usually exempt from epidemic visitation. This comparative immunity accords entirely with the very light rainfall, under ten inches annually. The country is "in the fork between the monsoon influences "; 9 but the remarkable point is that the populated tracts herethe lowlands bordering the rivers-are quite independent of rainfall. They are well watered by inundation, percolation, and irrigation channels from their respective rivers ; yet they with difficulty receive and propagate cholera infection. It is to be noticed that these valleys are not only watered; they are drained also by the rivers. The subsoil water is mostly not stagnant, as in Lower Bengal ; still there are to be found areas, adverted to above, "covered either by marshes or by stagnant pools." It is evident that drainage alone is not the solution of the opposition to the spread of cholera here. It is, I think, plain that the water of these rivers is not under ordinary conditions well suited to the growth of cholera. Hunter ${ }^{10}$ says: "The water (of the Indus) derived from the snows of the Himalayas is ...... slightly charged with saline ingredients.

On an average the temperature of the water is $10^{\circ} \mathrm{F}$. lower than that of the air." The low temperature can, I presume, affect only the main currents, and not the water in the irrigation channels. A minor factor in diminishing the intensity of cholera may lie in the character of the soil. Compared with that of the old endemic area it is "less alluvial, and more dry and mineral in character.'

No notice of cholera in India is complete without a reference to the extraordinary rise in mortality and complete change of season displayed in years of Hurdwar fair epidemics. The inevitable spread throughout Sind suggests that in these years at least the Indus and its tributaries have constituted a main means of diffusion. There is no donbt that the virus in the course of development at these fairs has acquired a resisting power well in advance of that ordinarily seen. Two of the last three of these epidemics have fallen in Kambh fair years; the other was remarkable for very early and excessively hot weather. Possibly this made the river water a more congenial home for the cholera organism. The province of Sind has the same "wide expanse of desert sand," extreme heat, and even more scanty rainfall ; but there is one important distinguishing feature: the country is much lower than the Punjab plains, and in places below the bed of the river, "whose overflowing waters are the sole means of distributing fertility through that parched region. ...... Considerable tracts of marshy land are to be found caused by changes in the course of the Indus." "The wide presence of stagnant surface and subsoil water explains the increased liability to cholera. The flood seasons at intervals of some years have been characterised by severe epidemics; and the bighest mortality bas been reached in the Karachi district, which embraces the delta of the Indus. But there is a quite different ciass of country, in which cholera is, if possible, even more closely associated with times of rain. I allude to the tracts of "black cotton soil " which make up the province of Berar and are found in the Bombay Presidency, the Deccan, the Central Provinces, and other

5 Hunter's Imperial Gazetteer. 6 History of Cholera in India. 9 Bryden, loc. cit. 10 Loc. cit. $\quad$ 1L IIunter, loc. cit. districts. This soil is exceedingly rich and intensely hygroscopic." "If exposed to moist air it will absorb eight per cent. of its own weight. ...... In wet weather the surface is converted into a deep tenacious mud." 12 This soil impresses characteristic features on the prevalence of cholera in districts where it is found. These features are seen most typically in the Berar valley, which is well watered by a fairly plentifal rainfall and by drainage from the enclosing hills. "The soil of the valley is one vast superstratum of black loam." 13 Eipidemic cholera in this province is generally entirely confined to the rainy season, and the severer visitations have mostly come when the rain bas been unusually heary. Owing to the remarkable retention of water by the soil, there is often great scarcity of water even for drinking purposes in the hot weather, and "the ground water lies at a very considerable depth." 1. "The hygroscopic nature of the soil no doubt accounts for the limitation of cholera epidemics to the rainy season. ${ }^{15}$ It may also account for the extremely high mortality occasionally exhibited, such as is approached by that of no other province in India. The excessive retention of rain-water by this soil seems to indicate that it enters into a more than usually intimate union with the soil. It may thus constitate an exceptionally favourable culture medium ; and the richness of the soil may be an important feature in this connexion. As above suggested, it is possible that the effect of the opposite condition, sterility of the ground, is to be seen to a slight degree in the low cholera rates of the Punjab.

There is in relation to rainfall a medium type of cholera season, that of the Carnatic (meteorological area comprising the greater part of the Madras Presidency). Its features are well defined. The limit of either excess or deficit is soon reached. Kain is needed, but it must be light. There are here two rainy seasons. The summer, or south-west, monsoon gives only a light fall. It is immediately followed by the rather heavier north-east rains, from October onwards. In an average year the incidence of cholera is at a minimum in the hot weather. It acquires new life with the early rains. There is a short rise up to July or August. Increasingly copious rain then brings the mortality down to a second minimum in October, the month of heaviest rainfall. After this, the fall rapidly diminishing, the repressing force is lifted, and the incidence of cholera develops into the chief epidemic of the year. The effect, of the heavier rain here is remarkable. Generally speaking, it does not lead to floods. ${ }^{16}$ There is no "submersion of breeding grounds," as used to be said of Lower Bengal in the rains ; and even in Lower Bengal it has to be explained how the water of wells and tanks in the unflooded areas becomes less noxions to the drinkers. The common idea of light showers carrying impurities into water supplies, while heavier rain fills the tanks and wells with a body of fresh and pare water, is good as far as it goes; but it scarcely explains the rise in mortality that marks the drying up of the rains. All that can be said regarding the depressing effect on the spread of cholera of heavy rainfall is that it is broadly a question of comparative purity of the water, of dilution of the poison.

Though in this rough sketch only the main types of a cholera season have been depicted as definitely influenced by rainfall, by far the larger portion of British India has been thus represented. The Central Provinces and the Bombay Province are so divided up in natural features as to need more

12 Captain Newbold, Journal of the Royal Asiatic Society. is Hunter, loc. cit.

Sanitary Commissioners of Berar, 1890.

16 I had expected to be able to give some definite information on the soil and water-supply of Madras. Unfortunately, it is not forthcoming The following extracts from the Government of India Sanitary Report for 1876 give. however, some idea of the supplies of the Carnatio meteorological area. Tanjore is taken as a type of the low-lying country near the sea, and Bellary of the higher ground above the Eastern Ghauts: "The district of Tanjore is an alluvial plain formed by the delta of the Kaveri River ...... the whole district is one highly irrigated rice-field. It is not a swamp, however, but an upraised delta, every part of which is well elevated above sea-level." Bellary: "In November [1876], however, the [cholera] mortality again commenced to rise, and continued to rise rapidly during the next four months. The effects of the drought, resulting from the deficient rainfall of 1876, began to be felt in Bellary early in October...... The great diminution in the mortality from cholera that occurred after NIarch [1877] was provably due to many tanks and streams having becomedry and the people being compelled to resort to the deep wells, in which the wate would be purer." Thus the low land may be taken as distinctly not waterlogged, like Lower Bengal; while on the higher ground it is only in quite exceptional drought that a low water-level may abolish the prevalence of cholera, as in Berar and the Punjab. This is a slight inrlication that this country may be regarded as of medium type iu water-supply as well as in the prevalence of eholera. 
detailed treatment than can here be devoted to them ; and in hilly, broken country, such as the Konkan (a part of the Bombay province), the conditions of water-supply being so obviously varied, it is not surprising to find that there is practically no cholera season there. The disease is here as likely to come at any one season as at any other. I think enough has been said to illustrate the fact that for the prevalence of free epidemic cholera a certain moderate amount and high level are needed in water-supplies, and that this quantity, being attained or approached at different periods of the year, according to locality and rainfall, is the main cause of seasonal variation of epidemics throughout India. The suggestion that the depressing influence of very heavy rain on the manifestation of cholera is simply the result of overdilution is further borne out by the following observation. It is that, generally speaking, heavy rain is capable of completely blotting out epidemic prevalence. It can only temporarily depress it. This is true of the very heavy rain of Assam and Bengal, and of the comparatively heavy northeast rains of the Carnatic. The only instance of a stronger influence than this that I have been able to find lies in the variations above normal of the light south-west monsoon in the Carnatic. This requires a little attention. The explanation probably lies in the fact that the period of the southwest monsoon is here to be regarded as the breeding season of epidemics, ${ }^{17}$ and a slight excess of rain at this period is fatal; whereas if the showers remain light the epidemic becomes established, and later heary rain can only temporarily check it. Some almost of the highest mortalities from cholera here have immediately followed excessive autumn rains.

From all this it is seen how the disease comes to be perennial in countries such as the old "endemic area." It is simply that the water-supply there is always at least sufficient ; on the other hand, scarcity (which means low level) of water, seen in Berar and in the Panjab, is the condition associated with complete seasonal disappearance of the disease. Of this there are at least two explanations. An obvious one is that the depth of water below the surface renders wells less liable to pollution, bat it is obviously also incomplete. I believe that the more influential factor is purely a matter of temperature. The stimulating influence of high temperatures on cholera is too well known to need support here. The depth of well water in these districts after the rains are over probably places it beyond the influence of a winter sun's rays; and, though the cholera organism may survive in these wells, its vitality is lowered and it is unable to multiply rapidly. But it must be acknowledged that even in Berar usually a few scattered pools persist in the river beds throughout the year; and there may be small outbreaks of the disease traceable to their use. Cholera has even on rare occasions, when the temperature has been persistently higher than normal, been mildly epidemic in the hot weather here. Probably on these occasions the sun's rays to some degree penetrated even to the deeper water levels. In the winter months this has never happened; the sun is not powerful enough. Hence there have been nothing beyond isolated cases and the smallest outbreaks. The influence of recession of water level below the surface in these countries of scanty supply is seen in the fact that they are the only provinces quite exempt from outbreaks and epidemics for a portion of the year; and the cold weather temperature of Berar is not lower than that of Lower Bengal or Assam. It will perhaps be as well to give another illustration of the effect of recession of water level and of atmospheric temperature on cholera intensity. In Lower Bengal cholera is at a minimum during the rains because the organism is sparsely scattered through the flooded water supplies. It rapidly rises, with a falling water level, till December. The cholera material is now more concentrated, and the water level is still high enough to be within the influence of the sun's rays; but after this the well water still recedes, and, I presu me, does not get quite sufficiently heated. The mortality from cholera hence drops somewhat till February. The hot weather then begins, and the water level remains practically without further change. The consequence is that the organism revives, and the mortality rises to the maximum of the year in April. It is noteworthy that the rain of May at once depresses the cholera rate, though it produces no drop in temperature nor affects the level of wellwater. It must act by diluting the poison in the water of tanks.

The character of the increase of cholera in the greater part of India shows that the cholera organism may lie dormant in water-supplies, only exhibiting pathogenic properties (possibly owing simply to rapid multiplication) when the conditions of temperature, rainfall, pressure, \&c., are favourable. I have recently published papers ${ }^{18}$ showing so close a relation between the weather and the disease in Bombay, Madras, and-I think-Berar, that cholera must be widely endemic in these provinces : yet not so typically endemic as in Lower Bengal and the Assam valleys, tor the influence of human intercourse is more visible in outbreaks in the former provinces, though it is lost in the epidemic history of the provinces, each being considered as a whole. Probably the proportion of water-supplies in which the organism can find a permanent home is mach smaller than in the Gangetic delta ; yct they must be widely spread. On the other hand, in the Punjab and Sind cholera is almost on foreign soil. Judging from the results of the Hurdwar fair epidemics, human agencies here appear to have a larger influence on epidemic prevalence than have weather conditions. Endemicity and spread by infection stand at the two ends of a scale.

Confusion seems to have arisen between the terms "endemic" and "perennial," probably because both are characteristic of cholera in the delta of the Ganges. The fact that cholera is perennial in a district simply indicates the stagnation of subsoil water and its nearness to the surface. In some of the low-lying districts of Madras and Bombay the disease continues throughout the year; but there come breaks in its prevalence of one or more years. It is not. more endemic here than in districts of definite seasonal limitation. The disappearance of the disease on black cotton soil in the winter in no way implies a need of reinfection from without to start its next seasonal manifestation.

In conclusion, I have done little more in this paper than collect and connect a few well-known facts. The inferences drawn are some of them speculative. Though they cover all the facts as they are at present known to me, much more exact eviderce is needed before they can be regarded as other than mere suggestions, and the peculiarities of Indian water-supply must be taken into account. Generally speaking, there are two distinct sources of supply: (1) wells, usually shallow wells; and (2) surface water, including "tanks" or reservoirs, pools, and running streams; and the $t$ wo classes are generally combined in the one district. The result may be somewhat confusing. Shrinkage of tank supplies may mean concentration of specific poison in them, and hence increase of cholera. Carried a stage further, it may enforce a freer use of well water, possibly now pure, though being at a considerable depth. On the other hand, the influence of a moderately high level of well water may be counteracted by flooding of tanks and river beds.

Table showing Decrease in Cholera Mortality and Rainfall nestward from Lower Bengal.

\begin{tabular}{|c|c|c|}
\hline $\begin{array}{l}\text { District or } \\
\text { Collectorate. }\end{array}$ & $\begin{array}{l}\text { Average annual rain- } \\
\text { fall in inches at the } \\
\text { chief station of the } \\
\text { district. }\end{array}$ & $\begin{array}{l}\text { Cholera mortality, } \\
\text { average annual ratio } \\
\text { per 1cto of civil popu- } \\
\text { lation of the district. }\end{array}$ \\
\hline 24 Pergunnahs... ... & $61 \cdot 50$ & $2 \cdot 37$ \\
\hline $\begin{array}{lllll}\text { Patna } & \ldots & \ldots & \ldots & \ldots\end{array}$ & $43 \cdot 12$ & 1.57 \\
\hline Allahahad $\ldots \quad \ldots \quad \ldots$ & $38 \cdot 51$ & $1 \cdot 19$ \\
\hline $\begin{array}{llll}\text { Cawnpore } & \ldots & \ldots & \ldots\end{array}$ & $31 \cdot 29$ & 0.65 \\
\hline $\begin{array}{lllll}\operatorname{Dell} i \mathrm{i} & \ldots & \ldots & \ldots & \ldots\end{array}$ & $28 \cdot 00$ & 0.37 \\
\hline $\begin{array}{llll}\text { Mooltan } & \ldots & \ldots & \ldots\end{array}$ & $6 \cdot 90$ & $0 \cdot 18$ \\
\hline
\end{tabular}

Rajkote, Kattywar, India.

\section{THE TREATMENT OF PROLAPSUS RECTI BY GALVANISM.}

By R. B. MITCHELL, M.D. EdIN.,

MEDICAI STPERINTEXDENT OF MIDLOTHIAY AND PEEDLTS DISTRICT LENATIC ASYLEM.

THE treatment of prolapsus recti by galvanism, though not mentioned in any works on surgery that $I$ have seen, would still appear to be of some value; and the fact that $I$ have 